\title{
Genetic divergence analysis of lime
}

\author{
M. M. Rahman and M. A. Z. Al Munsur ${ }^{1}$ \\ Department of Horticulture, Bangladesh Agricultural University, Mymensingh-2202, Bangladesh \\ ${ }^{1}$ Department of Biotechnology, Bangladesh Agricultural University, Mymensingh-2202, Bangladesh
}

\begin{abstract}
Genetic divergence of 40 lime accessions was estimated using $D^{2}$ and principal component analysis. The genotypes under study fell into 6 clusters. The distribution pattern indicated that the maximum number of genotypes were included in cluster III and the minimum number in cluster VI. The inter cluster distance in most of the cases were higher than the intra cluster distance indicating wider genetic diversity among the accessions of different groups. The highest inter cluster distance was observed between cluster II and III (1568.51) followed by cluster II and VI (1223.72) showing wide diversity among the groups. The highest intra-cluster distance was observed for the cluster III and the lowest for the cluster VI. Leaf area and number of stamen showed maximum contribution towards total divergence among the genotypes.
\end{abstract}

Keywords: Genetic Divergence, Lime, PCA, Genetic diversity

\section{Introduction}

Lime (Citrus aurantifolia L.), popularly known as "Kagzi lebu" in Bangladesh (Ahmad, 1982), is one of the most recognized Citrus fruit crops in the world. It is an important commercial Citrus fruit. As lime contains important limiting vitamin like vitamin- $\mathrm{C}$ and minerals like calcium and iron, it can overcome the malnutrition problem. Lime has some medicinal value also (Reuther et al., 1967). It works against asthma and also as antidepressant, stress relief, colds, flue, fever, nosebleeds, mouth ulcers, throat infections and boils (Tesserland, 1995).

Genetic diversity is an important factor in any crop improvement programme for obtaining high yielding variety. Multivariate analysis such as $D^{2}$ cluster and factor analysis have been proved to be useful in selecting accessions for hybridization. Mahalanobis (1949) $D^{2}$ anlysis has been successfully used in measuring the diversity in several crops. An understanding of nature and magnitude of variability among the existing lime germplasm is a prerequisite for its improvement. Divergence analysis is a useful tool in quantifying the degree of divergence between biological population of geographical level and to access in assessing relative contribution of different components to the total divergence both at intra and inter cluster levels (Jatasra and Paroda, 1978). Precise information on the nature and degree of genetic divergence helps the plant breeder in choosing the diverse parents for purposeful hybridization (Arunachalam, 1981; Samsuddin, 1985). Since published work on lime is scanty, the present study has been undertaken with 40 lime accession to understand the nature and magnitude of genetic divergence and the characters contributing genetic diversity by $D^{2}$ analysis.

\section{Materials and Methods}

The experiment was conducted at the field and laboratory of the "Collection, Evaluation, Conservation and Utilization of Landraces and Wildrelatives of some Important Vegetables and Fruits of Bangladesh (CVFB)" project, Department of Horticulture and Central Laboratory of Bangladesh Agricultural University, Mymensingh. The field experiment was laid out in the Randomized Complete Block Design (RCBD) with three replications. Data were recorded from 5 plants randomly selected from the plot of each replication on plant height, leaf area, number of stamen, fruit length, fruit circumference, rind thickness, fruit weight, per cent fruit set and yield of fruit per plant. Genetic diversity was studied following Malanobsis's (1949) generalized distance $\left(D^{2}\right)$ extended by Rao (1952). Clustering of genotypes was done according to Tocher's Method (Rao, 1952) and principal component analysis was done according to (Rao, 1964). All the statistical analyses were carried out using GENSTAT-5 computer software. Average intracluster distance was calculated by the following formula as suggested by Singh and Chaudhury (1985). 
Average intracluster $D^{2}=\sum \frac{D^{2} i}{n}$

Where, $\Sigma D^{2} i=$ Sum of distances between all possible combination $(n)$ of the varieties/lines included in a cluster

$\mathrm{n}=$ All possible combinations

\section{Results and Discussion}

In this study the fourty accessions of lime were grouped into six clusters based on $D^{2}$ values (Table 1). The distribution pattern indicate that the maximum number of genotypes were included in cluster III followed by cluster I and the minimum number of genotypes in cluster VI. Pande and Ghorai (1987) classified 48 genotypes of lime and grouped into 10 clusters. Surek and Korkut (1996) studied genetic divergence of 52 genotypes and grouped into 5 clusters.

Table 1. Distribution of 40 lime accessions in six clusters with location

\begin{tabular}{|c|c|c|c|c|}
\hline Cluster & Members & Percent & Accessions & Location \\
\hline \multirow[t]{2}{*}{ I } & \multirow[t]{2}{*}{8} & \multirow[t]{2}{*}{20.00} & $\begin{array}{l}\text { CA01, CA16, CA26, CA42, CA43, } \\
\text { CA49, CA50 }\end{array}$ & Mymensingh \\
\hline & & & CA24 & Khagrachari \\
\hline \multirow{4}{*}{ II } & \multirow{4}{*}{5} & \multirow{4}{*}{12.50} & CA02, CA44 & Mymensingh \\
\hline & & & CA17 & Comilla \\
\hline & & & CA18 & Bogra \\
\hline & & & CA32 & Jessore \\
\hline \multirow{6}{*}{ III } & \multirow{6}{*}{9} & \multirow{6}{*}{22.50} & CA03, CA39, CA41 & Mymensingh \\
\hline & & & CA21, CA22 & Dinajpur \\
\hline & & & CA23 & Khagrachari \\
\hline & & & CA27 & Chittagong \\
\hline & & & CA29 & Satkhira \\
\hline & & & CA47 & Rajshahi \\
\hline \multirow{3}{*}{ IV } & \multirow{3}{*}{7} & \multirow{3}{*}{17.50} & CA04, CA31, CA33, CA45 & Mymensingh \\
\hline & & & CA13, CA14 & Rajshahi \\
\hline & & & CA30, & Satkhira \\
\hline \multirow{4}{*}{ V } & \multirow{4}{*}{7} & \multirow{4}{*}{17.50} & CA25, CA28, CA48 & Mymensingh \\
\hline & & & CA06, CA10, & Pabna \\
\hline & & & CA15, & Rajshahi \\
\hline & & & CA19, & Bogra \\
\hline \multirow{3}{*}{ VI } & \multirow{3}{*}{4} & \multirow{3}{*}{10.00} & CA09, CA46 & Tangail \\
\hline & & & CA08 & Pabna \\
\hline & & & CA11 & Tangail \\
\hline
\end{tabular}

Genetic diversity is generally associated with geographical diversity but the former is not necessarily directly related with geographical distribution. This indicated that the geographical and genetic distributions did not follow the same trend as was reported by Latif Akanda et al. (1999), and Surek and Korkut (1996). Intra and inter cluster distances are presented in Table 2. The inter-cluster distances were higher than the average intra-cluster distances, which indicated wide genetic diversity among the lime accessions of different groups than those of same cluster. This finding was similar with the findings of Uddin and Mitra (1994). They obtained higher intercluster distances than the intracluster distance in multivariate analysis in sesame. The highest inter cluster distance was observed between cluster II and III (1568.51) and followed by cluster II and VI (1223.72) and the lowest between I and IV (374.97) (Table 2). The highest intra- cluster distance was observed for the cluster III and the lowest for the cluster VI. The highest values of intercluster distance indicated that the accessions belonging to cluster III was far way from those of cluster II. The minimum intercluster divergence was observed between IV and VI indicating that the genotype of these cluster were genetically close. 
Table 2. Average intra (bold) and inter-cluster distances for 40 lime accessions

\begin{tabular}{|c|c|c|c|c|c|c|}
\hline Cluster & I & II & III & IV & V & VI \\
\hline I & $\mathbf{2 8 4 . 3 7}$ & 596.236 & 883.27 & 374.97 & 815.09 & 591.78 \\
\hline II & & $\mathbf{4 3 0 . 1 6}$ & 1568.51 & 641.35 & 1111.23 & 1223.72 \\
\hline III & & & 440.38 & 675.24 & 1189.74 & 777.01 \\
\hline IV & & & & $\mathbf{2 5 4 . 7 2}$ & 511.82 & 396.13 \\
\hline V & & & & & 383.20 & 516.56 \\
\hline VI & & & & & & $\mathbf{2 2 1 . 5 9}$ \\
\hline
\end{tabular}

The maximum inter cluster distance between II and III suggested that they were if chosen for hybridization program, may give high heterotic $F_{1} s$ and broad spectrum of variability in segregating generations. This result supports with the findings of Samal and Jagadev (1996) and Ahmed et al. (2002). Divergence were given greater emphasis for deciding the type of cluster for the purpose of further selection and the choice of parents for hybridization (Jagadev and Samal, 1991). Higher inter and intra-cluster distances indicates higher genetic variability among accessions between and within clusters, respectively. The minimum inter and inter-cluster distance indicates closeness among the accessions of two clusters and within the clusters.

Based on the cluster means (Table 3) the important cluster was II for Number of stamen, fruit weight, per sent fruit set and yield of fruit per plant, IV for fruit length and fruit circumference, VI for leaf area and $V$ for plant height. Cluster III had the highest mean for Number of stamen, fruit weight, per sent fruit set and yield of fruit per plant and almost lowest for rind thickness. Cluster IV had highest mean for fruit length and fruit circumference, cluster VI had highest mean for leaf area and cluster $V$ had highest mean for plant height. It could be concluded that highest number of stamen, fruit weight per cent fruit set, yield of fruit per plant, lowest rind thickness and medium plant height from cluster II, lime accessions for highest fruit length and fruit circumference from cluster IV and highest leaf area from cluster $\mathrm{V}$ could be selected as parents for hybridization program. Accessions among the cluster separated by high $D^{2}$ values could be used in hybridization program for obtaining wide spectrum of variations among the segregates (Seetharaman et al., 1988). It is revealed that crosses should be made between accessions belonging to the distant clusters for high hetorotic response.

Table 3. Cluster mean values for yield and yield contributing characters of $\mathbf{4 0}$ lime accessions

\begin{tabular}{|c|c|c|c|c|c|c|c|c|c|}
\hline Cluster & $\begin{array}{c}\text { Plant } \\
\text { height } \\
(\mathrm{m})\end{array}$ & $\begin{array}{c}\text { Leaf area } \\
\left(\mathrm{cm}^{2}\right)\end{array}$ & $\begin{array}{c}\text { Number of } \\
\text { stamen }\end{array}$ & $\begin{array}{c}\text { Fruit } \\
\text { length } \\
(\mathrm{cm})\end{array}$ & $\begin{array}{c}\text { Fruit circum- } \\
\text { ference } \\
(\mathrm{cm})\end{array}$ & $\begin{array}{c}\text { Rind } \\
\text { thickness } \\
(\mathrm{cm})\end{array}$ & $\begin{array}{c}\text { Fruit } \\
\text { weight } \\
(\mathrm{g})\end{array}$ & $\begin{array}{c}\text { Per cent } \\
\text { fruit set }\end{array}$ & $\begin{array}{c}\text { Yield of } \\
\text { fruit per } \\
\text { plant (kg) }\end{array}$ \\
\hline I & 1.19 & 14.38 & 25.08 & 5.99 & 14.37 & 0.44 & 89.11 & 53.53 & 6.84 \\
\hline II & 1.49 & 18.38 & 26.33 & 6.46 & 14.62 & 0.39 & 98.91 & 74.43 & 10.72 \\
\hline III & 1.36 & 17.99 & 26.18 & 5.04 & 13.12 & 0.38 & 41.27 & 44.08 & 2.80 \\
\hline IV & 1.49 & 20.51 & 25.38 & 6.29 & 14.91 & 0.54 & 83.02 & 52.80 & 5.19 \\
\hline V & 1.91 & 14.77 & 24.72 & 6.27 & 14.71 & 0.41 & 81.95 & 42.08 & 3.29 \\
\hline VI & 1.38 & 20.58 & 24.95 & 6.05 & 14.34 & 0.45 & 93.39 & 33.85 & 1.38 \\
\hline
\end{tabular}

Eigen value of principal component axes of total variation accounting for them obtained from principal component analysis are presented in Table 4. The results reaveled that the first axis largely accounted for the variation among the lime accessions (31.99\%) followed by second axis (21.09\%). The first 5 axes accounted $85.24 \%$ of the total variation among 9 characters describing 40 lime accessions, while the first two accounted $53.09 \%$. 
Table 4. Latent root (Eigen value) and per cent of variation in respect of nine characters in $\mathbf{4 0}$ lime accessions

\begin{tabular}{|l|c|c|c|}
\hline \multicolumn{1}{|c|}{ Plant characters } & Eigen value & $\begin{array}{c}\text { Per cent of } \\
\text { Variance }\end{array}$ & $\begin{array}{c}\text { Cumulative } \\
\text { Percentage }\end{array}$ \\
\hline Plant height $(\mathrm{m})$ & 2.879 & 31.99 & 31.99 \\
\hline Leaf area $\left(\mathrm{cm}^{2}\right)$ & 1.898 & 21.09 & 53.09 \\
\hline Number of stamen & 1.269 & 14.10 & 67.20 \\
\hline Fruit length $(\mathrm{cm})$ & 0.928 & 10.31 & 77.52 \\
\hline Fruit circumference $(\mathrm{cm})$ & 0.696 & 7.73 & 85.24 \\
\hline Rind thickness $(\mathrm{cm})$ & 0.498 & 5.54 & 90.78 \\
\hline Fruit weight $(\mathrm{g})$ & 0.409 & 4.55 & 95.34 \\
\hline Per cent fruit set & 0.293 & 3.26 & 98.59 \\
\hline Yield of fruit per plant $(\mathrm{kg})$ & 0.126 & 1.40 & 100.0 \\
\hline
\end{tabular}

Group constellation were also independently developed by using principal component analysis (PCA) to verify grouping obtained through $D^{2}$ statistics in two-dimensional $Z_{1}-Z_{2}$ chart (Table 5). Contribution of the characters towards divergence of the genotypes the results of PCA revealed that in vector I $\left(Z_{1}\right)$ the important characters responsible for genetic divergence in the major axis of differentiation were plant height (0.0123), and number of stamen (0.0093) (Table 5).

Table 5. Latent vectors for seven characters 40 lime accessions

\begin{tabular}{|l|c|c|}
\hline Characters & Vector-I $\left(Z_{1}\right)$ & Vector-II $\left(Z_{2}\right)$ \\
\hline Plant height $(\mathrm{m})$ & -0.0013 & -0.0056 \\
\hline Leaf area $\left(\mathrm{cm}^{2}\right)$ & 0.0123 & 0.0263 \\
\hline Number of stamen & 0.0093 & 0.0150 \\
\hline Fruit length $(\mathrm{cm})$ & -0.0163 & -0.0018 \\
\hline Fruit circumference $(\mathrm{cm})$ & -0.0227 & -0.0061 \\
\hline Rind thickness $(\mathrm{cm})$ & -0.0006 & -0.0009 \\
\hline Fruit weight $(\mathrm{g})$ & -0.9843 & -0.1715 \\
\hline Per cent fruit set & -0.1663 & 0.9694 \\
\hline Yield of fruit per plant $(\mathrm{kg})$ & -0.0482 & 0.1727 \\
\hline
\end{tabular}

In vector II $\left(Z_{2}\right)$ which was second axis of differentiation, percent fruit set (0.9694), fruit yield/plant $(0.1727)$, leaf area $(0.0263)$ and number of stamen $(0.015)$ were important. The PCA analysis revealed that the vectors (I and II) were positive for leaf area and number of stamen. Such results indicated that those three characters contributed maximum towards divergence. Negative values in both the vectors for indicated that the lowest contribution to the total divergence. The greater divergence in the present materials is due to these three characters which will offer a good scope for improvement of yield through rational selection of parents for producing heterotic lime hybrid.

\section{References}

Ahmad, K.U. 1982. Gardener's Book of Production and Nutrition. Mumtaj Kamal, anglow No. 2, Krishi Khamar Sharak, Farm Gate, Dhaka-1215. p. 247.

Ahmed, A.U., M. A. Sarker, J.A. Choudhury, N. Ara and Ali, M. M. 2002. Genetic divergence analysis in chickpea. Bangladesh J. Agril. Res. 27(1): 47-50.

Arunachalam, V. A. 1981. Genetic distances in plant breeding. Indian J. Genet. 4: 226-236.

Jagadeb, P.N. and Samal, K.M. 1991. Multivariate analysis in niger (Guizotica abyssinicacass). Indian J. Genet. 30(1): 212221. 
Jatasra, D.S. and Paroda, R.S. 1978. Genetic divergence in wheat under different environmental conditions. Cereal Res. Comm. 6: 307-317.

Latif Akanda, M.A., Alam, M.S. and Shamsuddin, A.K.M. 1999. Genetic divergence analysis in groundnut (Arachis hypogaea L.). J. Asiat. Soc. Bangladesh Sci. 25(2): 293-298.

Mahalanobis, P.C. 1949. Historical note on the $D^{2}$ statistics. Sankhya, 19: 237-239.

Pande, K.R. and Ghorai, D.P. Genetic divergence in rice. Oryza. 24(4): 353-357.

Rao, C.R. 1964. The use and interception of principal analysis in applied research. Sankhya 22: 317-318.

Rao, C.R. 1952. Advanced Statistical Methods in Biometrical Research. Johan Willy and Sons. New York.

Reuther, W., Batchelor, L.D. and Webber, H.J. 1967. The Citrus Industry. Univ. Calif. Div. Agril. Sci., USA. pp. 534-537.

Samal, K.M. and Jagadeb, N. 1996. Genetic divergence among chickpea cultivars. Indian J. Genet. 56(1): 86-88.

Samsuddin, A.K.M. 1985. Genetic diversity in relation to heterosis and combining analysis in spring wheat. Theor. Appl. Genet. 70: 306-308.

Seetharaman, R., De, N., Sinha, R.M.K., and Banergee, S.P. 1988. Genetic divergence in rice. Indian J. Genet. 48: 189-194

Singh, R.K. and Chaudhury, B.D. 1985. Biometrical Methods of Quantitative Genetic Analysis. Harayana J. Hort. Sci. 12(1): 151-156.

Surek, H. and Korkut, K.Z. 1996. Heterosis for yield and yield components in rice (Oryza sativa L.) under temperate conditions. J. Bangladesh Plant Breed. Genet. 9(1\&2): 33-39.

Tisserland, R. 1995. Essential oil safety. Churchill Livingstone. p.64

Uddin, M.J. and Mitra, B.N. 1994. Variability of some quantitative characters in sesame (Sesamun indicum L). Bangladesh J. Agric. Sci. 19: 17-22. 